\title{
Coordinating a Dual-Channel Supply Chain Under Equal-price Mechanism When Demand Disruption Occurs
}

\author{
Xiaozhi $\mathrm{Wu}$ and Hong Chen \\ School of Management and Economics \\ University of Electronic Science and Technology of China, Chengdu, China \\ fjfzwxz@163.com
}

\begin{abstract}
This paper studies a two-stage dual-channel supply chain composed of one manufacturer and one traditional retailer. The manufacturer has its own online channel when he sells its product to the offline retailer. There exists a Stackelberg game between the manufacturer and the traditional retailer, in which the manufacturer is the leader and the traditional retailer is the follower. The manufacturer sets the online retail price which is the same as the offline retail price. When the supply chain is in static (undisrupted) scenario, its Pareto improvement can be obtained and it can be coordinated by the two-part-tariff contract with one-time transfer payment. When disruptions make the market scale change, the supply chain performance such as the optimal retail price, the optimal production quantity and the optimal total supply chain profit under different demand disruptions in the centralized supply chain can be obtained. Then, we find that there exists certain robustness in the manufacturer's production quantity. When the supply chain is decentralized, the supply chain coordination can be obtained by changing the wholesale price and one-time transfer payment according to different disruption levels. Finally, some numerical examples are presented to illustrate the results.
\end{abstract}

Keywords: Demand disruption, Price Mechanism, Two-part-tariff contract, Supply Chain Coordination

\section{Introduction}

Recently, large retail companies begin to establish their own online channels and are committed to promoting the "Online-to-Offline" mode, a new marketing mode, and sets the same retail price in both online and offline channels. Many large retail giants such as Suning, Gome, two companies in China, and Wal-mart \& YHD have also started constructing e-stores used to attract consumers, where the online retail price and the offline one are the same. On the other hand, electric retail giant such as T-mall, an e-commerce company in China, also begins to construct offline experience shops. Although price mechanism is still faced with some problems in practice, it has become a popular tool to coordinate the dual-channel supply chains due to the development of electronic commerce.

With the development of society and economy, E-commerce has become an important business mode for manufacturers and retailers to do their business. A supply chain in which a supply chain member (manufacturer/retailer) which simultaneously owns electronic commerce channel and traditional retail channel forms dual-channel supply chain structure. Several studies have investigated the operation of dual-channel supply chains. Choi (1996) studies price competition in a dual-channel supply chain where there exist duopoly manufacturers and duopoly common retailers. Chiang (2003) investigates a dual-channel supply chain structure which is based on utility theory and consumer demand model. Chen, et al., (2008) study a dual-channel supply chain, in which there exists service competition between direct channel and traditional channel. The supply 
chain can be coordinated by some contracts such as wholesale price contract, revenue-sharing contract, buyback contract and other supply chain contracts (Cachon, et al., 2003). Tsay (2004) studies how direct channel affects manufacturer-reseller relationship in a dual-channel supply chain. Dumrongsiri, et al., (2008) studies how marginal costs of direct and indirect channel affect the decisions of dual-channel supply chain's members. Hua (2010) investigates how the delivery lead time in the direct channel affects the manufacturers and retailer's pricing strategy in a dual-channel supply chain. Cai (2010) investigates how different dual-channel supply chain structures affect their members' decision and the corresponding supply chain's decision. Chen et al., (2012) examine how a manufacturer makes his pricing decision in a dual-channel supply chain and how to coordinate the supply chain with a wholesale price contract and a complementary contract. Ryan, et al., (2013) propose an improved revenue-sharing contract and a gain/loss sharing contract to coordinate a dual-channel supply chain. Ma, et al., (2013) examine how subsidy offered by the Chinese government influences the operation of a dual-channel closed-loop supply chain. Xu, et al., (2014) examine how to coordinate a dual-channel supply chain by using a two-way revenue sharing contract, in which the agents of the supply chain are risk averse. Mukhopadhyay, et al., (2008) investigate how to design an optimal contract and eliminate channel conflict in a mixed supply chain structure, in which there exists incomplete cost information about the retailer's adding value. Cao, et al., (2013) examine a wholesale contract design problem in a dual-channel supply chain, in which there exists asymmetric cost information in the supply chain members' game.

How to control inventory is also a hot issue which firms and researchers are interested in. Cachon (2001) investigates how to select inventory policies in a supply chain consisting of one supplier and $\mathrm{N}$ retailers. Boyac1, et al., (2002) study pricing and lot sizing decisions in a supply chain consisting of one wholesaler and one or more retailers, and concentrate heavily on transfer prices and ownership of retail-inventory. Chiang and Monahan (2005) investigate how to deal with inventory transshipment problem in a dual-channel inventory model when stockout happens in one channel (online channel or offline channel). Geng and Mallik (2007) study how to select an optimal inventory allocation strategy in a dual-channel supply chain when each channel in the supply chain faces a stochastic demand. Yao, et al., (2009) compare the optimal inventory levels and the corresponding expected profits in a dual-channel supply chain when three inventory strategies are applied. Takahashi, et al., (2011) study an inventory control model in a dual-channel supply chain, in which inventory holding cost, lost sales cost and production and delivery cost are included.

Disruptions have a deep effect on the operation of supply chains. Natural disasters such as earthquakes, tsunamis and landslides, public health emergencies which include SARS, avian flu, and man-made emergencies such as terrorist attacks affect the operation of stable supply chains. To cope with the supply chain's disruptions has become a very valuable issue for companies around the world. Qi, et al., (2004) introduce the idea of disruption management in supply chain research. In their paper, they examine how to coordinate a one-supplier-one-retailer supply chain when demand disruption occurs. Based on disruption management, many researchers have extended their studies in various scenarios. Yang, et al., (2005) study how to adjust a production plan when incidents such as market change, supply shortage and machine breakdown in a manufacturer happen. $\mathrm{Xu}$, et al., (2006) investigate how to coordinate a one-supplier-one-retailer supply chain when production cost disruption happens, and extend the problem to multiple retailers. Qi, et al., (2006) analyze how to update a machine scheduling problem concerning deviation cost when disruption happens. Huang, et al., (2006) investigate how to coordinate a dyadic supply chain when the retailer faces an exponential demand function. Xiao and $\mathrm{Yu}$ (2006) study two-vertically integrated supply chain channel in which there are one manufacturer and multiple retailers in each channel, and examine how demand and supply 
disruptions affect the retailers' marketing strategies. Lei, et al., (2012) investigate how to coordinate a supply chain in asymmetric information scenario when demand and cost disruptions occur simultaneously. Xiao, et al., (2005) study how to deal with sales promotion investment and demand disruption in a supply chain, in which there are one manufacturer and two competing retailers. Xiao, et al., (2007, 2008) study how to coordinate the same supply chain structure as that in Xiao, et al., (2005) when demand disruptions and cost disruptions happen, respectively. Huang, et al., (2012) consider the disruption management in a dual-channel supply chain when demand disruptions occur. Huang, et al., (2013) also study a pricing and production problem in a dual-channel supply chain when production cost disruptions occur.

However, there are few researches which examine the effect of a particular contract on the coordination of a dual-channel supply chain when disruption happens. The same situation is true about the studies in exploring equal-price marketing model in dual-channel supply chains. In this paper, we will examine the following problems: price mechanism in the marketing model, the feasibility of coordinating a dual-channel supply chain with the two-part-tariff contract, the decisions in the supply chain when demand disruption occurs, and the problem of coordinating the supply chain with the two-part-tariff contract.

The rest of this paper is organized as follows. A basic model is established in Section 2. Section 3 analyzes the centralized decision of the dual-channel supply chain under the two-part-tariff contract without demand disruption and Section 4 analyzes the decision of the supply chain when demand disruption happens. Section 5 investigates how to coordinate the decentralized supply chain when demand disruption occurs. Some numerical examples are presented to certify the results derived from this paper in Section 6. Section 7 summarizes this paper.

\section{Basic Model}

There exist one manufacturer and one offline retailer in a two-stage supply chain. The manufacturer sells its product in both offline channel and online retail channel. The retail price in online channel is the same as that in offline channel.

\subsection{Notation}

The notation and parameters used in the model are shown in Table 1.

Table1: Notation and Parameters for the Problems

\begin{tabular}{ccc}
\hline Value & Description & Test values \\
\hline$a$ & Total market demand & 2000 \\
$b_{1}$ & Price coefficient in the online channel & 10 \\
$b_{2}$ & Price coefficient in the offline channel & 20 \\
$p$ & Unit sales price & Decision variable \\
$c$ & Unit manufacturing cost & 10 \\
$\Delta a$ & Unit demand disruption & $300,200,100,50$, \\
$k_{1}$ & Marginal cost when production plan increases & $-50,-100,-200,-300$ \\
$k_{2}$ & Marginal cost when production plan decreases & 5 \\
$p$ & Unit sales price after disruption & Decision variable \\
$w$ & The wholesale price of offline channel & Decision variable \\
\hline
\end{tabular}




\subsection{The Benchmark Model}

We construct a demand function concerning both online channel and offline channel:

$$
\left\{\begin{array}{c}
q_{1}=\mu a-b_{1} p \\
q_{2}=(1-\mu) a-b_{2} p
\end{array}\right.
$$

The total profit function is determined by the following equation:

$$
\Pi=(p-c)\left(\mu a-b_{1} p\right)+(p-c)\left[(1-\mu) a-b_{2} p\right]
$$

We obtain the optimal solution by solving the first-order condition, i.e., $\partial \Pi / \partial p=0$.

Thus, the optimal sales price is $\bar{p}=\frac{a+\left(b_{1}+b_{2}\right) c}{2\left(b_{1}+b_{2}\right)}$, the optimal channel production quantities are

$$
\left\{\begin{array}{c}
\bar{q}_{1}=\mu a-\frac{b_{1}\left[a+\left(b_{1}+b_{2}\right) c\right]}{2\left(b_{1}+b_{2}\right)} \\
\bar{q}_{2}=(1-\mu) a-\frac{b_{2}\left[a+\left(b_{1}+b_{2}\right) c\right]}{2\left(b_{1}+b_{2}\right)}
\end{array},\right.
$$

and the total profit of the dual-channel supply chain is

$$
\bar{\Pi}=\frac{\left[\left(b_{1}+b_{2}\right) c-a\right]^{2}}{4\left(b_{1}+b_{2}\right)} .
$$

\section{Coordinating Dual-channel Supply Chain Under the Two-part-tariff Contract without Disruption}

In the dual-channel competition mechanism, the manufacturer is the leader and the retailer is the follower of this Stackelberg game, and the manufacturer determines the wholesale price and transfer payment. The offline retailer determines product quantity and sets the sale price in the supply chain.

Based on the Stackelberg game theory, the retailer's profit function can be written as

$$
\pi_{r}=(p-w)\left[(1-\mu) a-b_{2} p\right]-T .(3)
$$

The response function of the retailer's optimal retail price is $p=\frac{(1-\mu) a+w b_{2}}{2 b_{2}}$, the wholesale price is $w^{*}=\frac{a}{\left(b_{1}+b_{2}\right)}+c-\frac{a(1-\mu)}{b_{2}}$, and the retail price is $p^{*}=\frac{a+\left(b_{1}+b_{2}\right) c}{2\left(b_{1}+b_{2}\right)}=\bar{p}$. We obtain that the profit of the retailer is $\pi_{r}^{*}=\frac{\left(b_{2}^{2} c-a b_{2}-2 a b_{1}+b_{1} b_{2} c+2 \mu a b_{1}+2 \mu a b_{2}\right)^{2}}{4 b_{2}\left(b_{1}+b_{2}\right)^{2}}-T$, and the profit of the manufacturer is

$$
\pi_{d}^{*}=\frac{\left[\left(b_{1}+b_{2}\right) c-a\right]\left(b_{1}^{2} c+a b_{1}+b_{1} b_{2} c+2 \mu a b_{1}+2 \mu a b_{2}\right)}{4\left(b_{1}+b_{2}\right)^{2}}+\frac{a\left[2 a(1-\mu)\left(b_{1}+b_{2}\right)-b_{2}\left(a+b_{1} c+b_{2} c\right)\right]\left(\mu b_{1}-b_{1}+\mu b_{2}\right)}{2 b_{2}\left(b_{1}+b_{2}\right)^{2}}+T,
$$

respectively.

The total profit of the supply chain is $\Pi^{*}=\left(\pi_{d}^{*}+\pi_{r}^{*}\right)=\bar{\Pi}$.

Lemma 1. If a dual-channel supply chain faces a demand function shown in Eq. (1), the participants' profits in the equal-price supply chain can achieve Pareto improvement and the total profit of the supply chain can be maximized by the two-part-tariff pricing $\operatorname{contract}(w, T)$ where

$$
\begin{gathered}
w^{*}=\frac{a}{\left(b_{1}+b_{2}\right)}+c-\frac{a(1-\mu)}{b_{2}} \text {, and } \\
T^{*} \in\left[\frac{\left(b_{2}^{2} c-a b_{2}-2 a b_{1}+b_{1} b_{2} c+2 \mu a b_{1}+2 \mu a b_{2}\right)^{2}}{4\left(b_{1}+b_{2}\right)^{2}\left(b_{1}+2 b_{2}\right)}, \frac{\left(2 b_{1}+3 b_{2}\right)\left(b_{2}^{2} c-a b_{2}-2 a b_{1}+b_{1} b_{2} c+2 \mu a b_{1}+2 \mu a b_{2}\right)^{2}}{4\left(b_{1}+b_{2}\right)^{2}\left(b_{1}+2 b_{2}\right)^{2}}\right] .
\end{gathered}
$$

Proof.

In the independent decision-making state without the contract, the profit function of 
the offline retailer is

$$
\pi_{r}=(p-w)\left[(1-\mu) a-b_{2} p\right] .
$$

The optimal price response function of the retailer is $p=\frac{(1-\mu) a+w b_{2}}{2 b_{2}}$.

The manufacturer's profit function is

$$
\pi_{d}=\left[\frac{(1-\mu) a+w b_{2}}{2 b_{2}}-c\right]\left[\mu a-b_{1} \frac{(1-\mu) a+w b_{2}}{2 b_{2}}\right]+(w-c)\left[\frac{(1-\mu) a-w b_{2}}{2}\right] .
$$

The optimal wholesale price is $w^{0}=\frac{b_{2} c-(1-\mu) a}{b_{2}}-\frac{b_{2} c-3 a+2 \mu a}{b_{1}+2 b_{2}}$.

Therefore, the retailer's profit in the dual-channel supply chain is

$$
\pi_{r}^{0}=\frac{\left(b_{2}^{2} c-a b_{2}-2 a b_{1}+b_{1} b_{2} c+2 \mu a b_{1}+2 \mu a b_{2}+a b_{1} b_{2} c\right)^{2}}{4 b_{2}\left(b_{1}+2 b_{2}\right)^{2}}<\pi_{r}^{*} .
$$

The difference between $\pi_{r}^{*}$ and $\pi_{r}^{0}$ is

$$
\pi_{r}^{*}-\pi_{r}^{0}=\frac{\left(2 b_{1}+3 b_{2}\right)\left(b_{2}^{2} c-a b_{2}-2 a b_{1}+b_{1} b_{2} c+2 \mu a b_{1}+2 \mu a b_{2}\right)^{2}}{4\left(b_{1}+b_{2}\right)^{2}\left(b_{1}+2 b_{2}\right)^{2}}-T .
$$

The manufacturer's profit is

$$
\pi_{d}^{0}=\frac{\left(6 a-4 \mu a+b_{1} c\right)^{2}}{16\left(b_{1}+2 b_{2}\right)}-\frac{(1+2 \mu) a c}{4}+\frac{\left(3 b_{1}+2 b_{2}\right) c^{2}}{16}-\frac{a^{2}(1-\mu)^{2}}{b_{2}} .
$$

The difference between $\pi_{d}^{*}$ and $\pi_{d}^{0}$ is

$$
\pi_{d}^{*}-\pi_{d}^{0}=\frac{\left(b_{2}^{2} c-a b_{2}-2 a b_{1}+b_{1} b_{2} c+2 \mu a b_{1}+2 \mu a b_{2}\right)^{2}}{4\left(b_{1}+b_{2}\right)^{2}\left(b_{1}+2 b_{2}\right)}+T .
$$

In order to achieve Pareto improvement, the profits of the manufacturer and the retailer should satisfy

$$
\left\{\begin{array}{l}
\pi_{d}^{*}-\pi_{d}^{0} \geq 0 \\
\pi_{r}^{*}-\pi_{r}^{0} \geq 0
\end{array} .\right.
$$

Therefore, the range of the one-time transfer payment is

$$
T \in\left[\frac{\left(b_{2}^{2} c-a b_{2}-2 a b_{1}+b_{1} b_{2} c+2 \mu a b_{1}+2 \mu a b_{2}\right)^{2}}{4\left(b_{1}+b_{2}\right)^{2}\left(b_{1}+2 b_{2}\right)}, \frac{\left(2 b_{1}+3 b_{2}\right)\left(b_{2}^{2} c-a b_{2}-2 a b_{1}+b_{1} b_{2} c+2 \mu a b_{1}+2 \mu a b_{2}\right)^{2}}{4\left(b_{1}+b_{2}\right)^{2}\left(b_{1}+2 b_{2}\right)^{2}}\right] .
$$

Q.E.D.

\section{Centralized Decision with Demand Disruption}

Centralized decision-making in the supply chain is to study the optimal total supply chain pricing and production plan in an integrated way. Some unexpected events occur after the manufacturer arranges production plan according to market forecast in stable state, which leads to some changes of the market scale. In the disruption model, the demand function of the supply chain is

$$
\left\{\begin{array}{c}
q_{1}=\mu(a+\Delta a)-b_{1} p \\
q_{2}=(1-\mu)(a+\Delta a)-b_{2} p
\end{array} .\right.
$$

As the result of the disruption, the manufacturer needs to increase the production quantity when $q_{1}+q_{2}>q_{1}^{*}+q_{2}^{*}$, and needs to reduce the production quantity when $q_{1}+q_{2}<q_{1}^{*}+q_{2}^{*}$. We assume that there is a central decision-maker who seeks to maximize the total supply chain profit after the uncertainty is resolved. The new expression for the supply chain profit function is determined by the following equation

$$
\Pi=(p-c)\left[a+\Delta a-\left(b_{1}+b_{2}\right) p\right]-k_{1}\left(q_{1}+q_{2}-q_{1}^{*}-q_{2}^{*}\right)^{+}-k_{2}\left(q_{1}^{*}+q_{2}^{*}-q_{1}-q_{2}\right)^{+},(5
$$

in which $(x)^{+}=\max \{x, 0\}$.

In Eq. (5), the second term on the right side of the equation is the cost associated with the increase of production quantity and the third term is the cost associated with the 
decrease of production quantity.

If $q_{1}+q_{2} \geq q_{1}^{*}+q_{2}^{*}$, the total profit of the supply chain can be rewritten as:

$$
\Pi_{1}=(p-c)\left[a+\Delta a-\left(b_{1}+b_{2}\right) p\right]-k_{1}\left(q_{1}+q_{2}-q_{1}^{*}-q_{2}^{*}\right) .
$$

If $q_{1}+q_{2} \leq q_{1}^{*}+q_{2}^{*}$, the total profit of the supply chain can be rewritten as:

$$
\Pi_{2}=(p-c)\left[a+\Delta a-\left(b_{1}+b_{2}\right) p\right]-k_{2}\left(q_{1}^{*}+q_{2}^{*}-q_{1}-q_{2}\right) \text {. }
$$

Lemma 2. Suppose that $\Pi$ in Eq. (5) is maximized by $\left(q_{1}^{*}, q_{2}^{*}\right)$. Then, $q_{1}^{*}+q_{2}^{*} \geq q_{1}^{*}+q_{2}^{*}$ if $\Delta a>0$, and $q_{1}^{*}+q_{2}^{*} \leq q_{1}^{*}+q_{2}^{*}$ if $\Delta a<0$.

Proof. Recall the baseline case that $Q=q_{1}+q_{2}$ and $\bar{Q}=q_{1}^{*}+q_{2}^{*}=\frac{a-c\left(b_{1}+b_{2}\right)}{2}$. Inserting the two values into Eq. (5), we obtain that $\Pi(Q)=\frac{\left[a-c\left(b_{1}+b_{2}\right)\right]^{2}}{4\left(b_{1}+b_{2}\right)}+\frac{\Delta a \bar{Q}}{\left(b_{1}+b_{2}\right)}$, which is maximized at $Q=\bar{Q}$ when $\Delta a=0$.

Suppose that $\Delta a>0$ and $q_{1}^{*}+q_{2}^{*}<q_{1}^{*}+q_{2}^{*}$. Then,

$$
\Pi\left(Q^{*}\right)=Q\left[\frac{a-Q}{\left(b_{1}+b_{2}\right)}-c\right]+\frac{\Delta a \bar{Q}}{\left(b_{1}+b_{2}\right)}-k_{2}(\bar{Q}-Q) \leq \frac{\left[a-c\left(b_{1}+b_{2}\right)\right]^{2}}{4\left(b_{1}+b_{2}\right)}+\frac{\Delta a \bar{Q}}{\left(b_{1}+b_{2}\right)}-k_{2}(\bar{Q}-Q)<\Pi(\bar{Q}) \cdot
$$

This contradicts the assumption that $\Pi(Q)$ is maximized at $\bar{Q}$. Therefore, we must have $q_{1}^{*}+q_{2}^{*} \geq q_{1}^{*}+q_{2}^{*}$ when $\Delta a>0$. Similarly, we get $q_{1}^{*}+q_{2}^{*} \leq q_{1}^{*}+q_{2}^{*}$ when $\Delta a<0$.

When the disruption suddenly happens and makes the consumer's demand increase, i.e., $\Delta a>0$, we obtain that

$$
\begin{aligned}
& \prod_{1}=(p-c)\left[a+\Delta a-\left(b_{1}+b_{2}\right) p\right]-k_{1}\left(q_{1}+q_{2}-q_{1}^{*}-q_{2}^{*}\right) . \\
& \text { s.t. } q_{1}^{*}+q_{2}^{*} \geq q_{1}^{*}+q_{2}^{*}
\end{aligned} .
$$

There are two cases in this scenario, which are shown as follows:

Case1: $\Delta a \geq k_{1}\left(b_{1}+b_{2}\right)$

The optimal retail price is $p_{1}^{*}=\frac{a+\Delta a+\left(k_{1}+c\right)\left(b_{1}+b_{2}\right)}{2\left(b_{1}+b_{2}\right)}$

$$
\text { and the optimal production quantity is }\left\{\begin{array}{c}
q_{11}^{*}=\mu(a+\Delta a)-\frac{b_{1}\left[a+\Delta a+\left(b_{1}+b_{2}\right)\left(c+k_{1}\right)\right]}{2\left(b_{1}+b_{2}\right)} \\
q_{21}^{*}=(1-\mu)(a+\Delta a)-\frac{b_{2}\left[a+\Delta a+\left(b_{1}+b_{2}\right)\left(c+k_{1}\right)\right]}{2\left(b_{1}+b_{2}\right)}
\end{array}\right. \text {. }
$$

Case2: $0<\Delta a<k_{1}\left(b_{1}+b_{2}\right)$

The optimal retail price is $p_{2}^{*}=p^{*}=\frac{a+\left(b_{1}+b_{2}\right) c_{m}+b_{1} c_{d}+b_{2} c_{r}}{2\left(b_{1}+b_{2}\right)}$

$$
\text { and the optimal production quantity is }\left\{\begin{array}{c}
q_{12}^{*}=q_{1}^{*}=\mu a-\frac{b_{1}\left[a+\left(b_{1}+b_{2}\right) c\right]}{2\left(b_{1}+b_{2}\right)} \\
q_{22}^{*}=q_{2}^{*}=(1-\mu) a-\frac{b_{2}\left[a+\left(b_{1}+b_{2}\right) c\right]}{2\left(b_{1}+b_{2}\right)}
\end{array}\right. \text {. }
$$

When the disruption suddenly happens and makes the demand decrease, i.e., $\Delta a<0$, we obtain that

$$
\begin{aligned}
& \Pi_{2}=(p-c)\left[a+\Delta a-\left(b_{1}+b_{2}\right) p\right]-k_{2}\left(q_{1}^{*}+q_{2}^{*}-q_{1}-q_{2}\right) . \\
& \text { s.t. } q_{1}^{*}+q_{2}^{*} \leq q_{1}^{*}+q_{2}^{*}
\end{aligned}
$$

There are also two cases in this scenario, which are shown as follows:

Case 3: $-k_{2}\left(b_{1}+b_{2}\right)<\Delta a<0$ 
Similar to case2, we get:

the optimal retail price is $p_{3}^{*}=\frac{a+\left(b_{1}+b_{2}\right) c}{2\left(b_{1}+b_{2}\right)}+\frac{\Delta a}{\left(b_{1}+b_{2}\right)}$

and the optimal production quantity is $\left\{\begin{array}{c}q_{13}^{*}=q_{1}^{*}=\mu a-\frac{b_{1}\left[a+\left(b_{1}+b_{2}\right) c\right]}{2\left(b_{1}+b_{2}\right)} \\ q_{23}^{*}=q_{2}^{*}=(1-\mu) a-\frac{b_{2}\left[a+\left(b_{1}+b_{2}\right) c\right]}{2\left(b_{1}+b_{2}\right)}\end{array}\right.$.

Case 4: $\Delta a \leq-k_{2}\left(b_{1}+b_{2}\right)$

Similar to case 1 , we get:

the optimal retail price is $p_{4}^{*}=\frac{a+\Delta a+\left(c-k_{2}\right)\left(b_{1}+b_{2}\right)}{2\left(b_{1}+b_{2}\right)}$

and the optimal production quantity is

$$
\left\{\begin{array}{c}
q_{14}^{*}=\mu(a+\Delta a)-\frac{b_{1}\left[a+\Delta a+\left(b_{1}+b_{2}\right)\left(c-k_{2}\right)\right]}{2\left(b_{1}+b_{2}\right)} \\
q_{24}^{*}=(1-\mu)(a+\Delta a)-\frac{b_{2}\left[a+\Delta a+\left(b_{1}+b_{2}\right)\left(c-k_{2}\right)\right]}{2\left(b_{1}+b_{2}\right)}
\end{array} .\right.
$$

Theorem 1. Suppose that a dual-channel supply chain faces a demand function shown in Eq. (1) and the profit function under the demand disruption is shown in Eq. (5). When the demand disruption occurs, the optimal retail price is

$$
p^{*}=\left\{\begin{array}{c}
\frac{a+\Delta a+\left(k_{1}+c\right)\left(b_{1}+b_{2}\right)}{2\left(b_{1}+b_{2}\right)}, \text { if } \Delta a \geq k_{1}\left(b_{1}+b_{2}\right) \\
\frac{a+\left(b_{1}+b_{2}\right) c}{2\left(b_{1}+b_{2}\right)}+\frac{\Delta a}{\left(b_{1}+b_{2}\right)}, \text { if }-k_{2}\left(b_{1}+b_{2}\right)<\Delta a<k_{1}\left(b_{1}+b_{2}\right) \\
\frac{a+\Delta a+\left(c-k_{2}\right)\left(b_{1}+b_{2}\right)}{2\left(b_{1}+b_{2}\right)}, \text { if } \Delta a \leq-k_{2}\left(b_{1}+b_{2}\right)
\end{array},\right.
$$

the optimal online sales quantity is

$$
q_{1}^{*}=\left\{\begin{array}{c}
\mu(a+\Delta a)-\frac{b_{1}\left[a+\Delta a+\left(b_{1}+b_{2}\right)\left(c+k_{1}\right)\right]}{2\left(b_{1}+b_{2}\right)}, \text { if } \Delta a \geq k_{1}\left(b_{1}+b_{2}\right) \\
\mu a-\frac{b_{1}\left[a+\left(b_{1}+b_{2}\right) c\right]}{2\left(b_{1}+b_{2}\right)}, \text { if }-k_{2}\left(b_{1}+b_{2}\right)<\Delta a<k_{1}\left(b_{1}+b_{2}\right) \\
\mu(a+\Delta a)-\frac{b_{1}\left[a+\Delta a+\left(b_{1}+b_{2}\right)\left(c-k_{2}\right)\right]}{2\left(b_{1}+b_{2}\right)}, \text { if } \Delta a \leq-k_{2}\left(b_{1}+b_{2}\right)
\end{array},\right.
$$

the optimal offline sales quantity is

$$
q_{2}^{*}=\left\{\begin{array}{c}
(1-\mu)(a+\Delta a)-\frac{b_{2}\left[a+\Delta a+\left(b_{1}+b_{2}\right)\left(c+k_{1}\right)\right]}{2\left(b_{1}+b_{2}\right)}, \text { if } \Delta a \geq k_{1}\left(b_{1}+b_{2}\right) \\
(1-\mu) a-\frac{b_{2}\left[a+\left(b_{1}+b_{2}\right) c\right]}{2\left(b_{1}+b_{2}\right)}, \text { if }-k_{2}\left(b_{1}+b_{2}\right)<\Delta a<k_{1}\left(b_{1}+b_{2}\right) \\
(1-\mu)(a+\Delta a)-\frac{b_{2}\left[a+\Delta a+\left(b_{1}+b_{2}\right)\left(c-k_{2}\right)\right]}{2\left(b_{1}+b_{2}\right)}, \text { if } \Delta a \leq-k_{2}\left(b_{1}+b_{2}\right)
\end{array},\right.
$$

and the optimal total profit in the supply chain is

$$
\Pi^{*}=\left\{\begin{array}{l}
\frac{\left[a+\Delta a-c\left(b_{1}+b_{2}\right)\right]^{2}-2 \Delta a\left(b_{1}+b_{2}\right) k_{1}+\left(b_{1}+b_{2}\right)^{2} k_{1}^{2}}{4\left(b_{1}+b_{2}\right)}, \text { if } \Delta a \geq k_{1}\left(b_{1}+b_{2}\right) \\
\frac{\left[a-c\left(b_{1}+b_{2}\right)\right]\left[a+2 \Delta a-c\left(b_{1}+b_{2}\right)\right]}{4\left(b_{1}+b_{2}\right)}, \text { if }-k_{2}\left(b_{1}+b_{2}\right)<\Delta a<k_{1}\left(b_{1}+b_{2}\right) \\
\frac{\left[a+\Delta a-c\left(b_{1}+b_{2}\right)\right]^{2}+2 \Delta a\left(b_{1}+b_{2}\right) k_{2}+\left(b_{1}+b_{2}\right)^{2} k_{2}^{2}}{4\left(b_{1}+b_{2}\right)}, \text { if } \Delta a \leq-k_{2}\left(b_{1}+b_{2}\right)
\end{array} .\right.
$$


It can be seen from theorem 1 :

(1) If unexpected events make the consumer's demand increase in the dual-channel supply chain, the retail price will increase. If unexpected events make the consumer's demand decrease in the supply chain, the retail price will decrease.

(2) If the unexpected events makes the consumer's demand market scale increase greatly, i.e., $\Delta a \geq k_{1}\left(b_{1}+b_{2}\right)$, the manufacturer will increase the corresponding production quantity, increase the online sales price and the online sales quantity, which, in turn, will make the offline sales quantity increase.

(3) If the unexpected events makes the consumer's demand decrease greatly, i.e., $\Delta a \leq-k_{2}\left(b_{1}+b_{2}\right)$, the manufacturer will reduce corresponding production quantity, decrease the online sales price and the online sales quantity, which, in turn, will make the offline sales quantity decrease.

(4) If the deviation of the consumer's demand is relatively small, i.e., $-k_{2}\left(b_{1}+b_{2}\right)<\Delta a<k_{1}\left(b_{1}+b_{2}\right)$, the central decision-maker needs to adjust retail price rather than the production quantity.

We will investigate the incremental improvement in the supply chain performance when there exists demand disruption in the following sections. To quantify the performance, we compare our results with the scenario in the decentralized dual-channel supply chain under the equal-retail-price mechanism.

\section{Decentralized Decision after Demand Disruption OSccurs}

In the dual-channel supply chain, double marginal effect happens when supply chain members act according to their own optimal decisions. The definition of coordination in dual-channel supply chain is that the total profit of a dual-channel supply chain in decentralized decision equals to that in centralized decision. That is to say, for a Stackelberg game in this paper, if decentralized decision in a dual-channel supply chain is made according to equal-price mechanism and the mechanism in decentralized decision makes the retail price that the retailer sets, i.e., $p^{T p *}$, equal to the optimal retail price in centralized decision, i.e., $p$, then the supply chain performance in decentralized decision is the same as that in centralized decision. In order to achieve Pareto improvement, the manufacturer needs to offer a one-time transfer payment $T$. The method is consistent with that used in stable state.

When the demand disruption occurs, the retailer's profit function is

$$
\pi_{r}=(p-w)\left[(1-\mu)(a+\Delta a)-b_{2} p\right]-T \cdot(10)
$$

Thus, the response function of the retailer's optimal retail price is

$$
\begin{aligned}
& \qquad p=\frac{(1-\mu) a+\Delta a)+w_{2} b}{2 b_{2}} \\
& \text { and that of the wholesale price is } w=2 p-\frac{(1-\mu)(a+\Delta a)}{b_{2}} .
\end{aligned}
$$

The profit function of the manufacturer is

$$
\pi_{d}=(p-c)\left[\mu(a+\Delta a)-b_{1} p\right]+(w-c)\left[(1-\mu)(a+\Delta a)-b_{2} p\right]+T .
$$

For the case 1, if $\Delta a \geq k_{1}\left(b_{1}+b_{2}\right)$,

the optimal wholesale price is $w_{1}^{*}=\frac{a+\Delta a}{\left(b_{1}+b_{2}\right)}+c+k_{1}-\frac{(1-\mu)(a+\Delta a)}{b_{2}}$ and the range of the

transfer payment is

$$
\begin{aligned}
& T_{1} \in\left[\frac{\left[2 b_{1}(a+\Delta a)(1-\mu)-c b_{1} b_{2}+b_{2}(a+\Delta a)(1-2 \mu)-c b_{2} b_{2}\right]^{2}-2\left(b_{1}+b_{2}\right) k_{1}\left[2 \Delta a b_{1}^{2}+(a+5 \Delta a) b_{2}^{2}-2 \mu b_{2}\left(b_{1}+b_{2}\right)(a+\Delta a)-c\left(b_{1}+b_{2}\right) b_{2}^{2}+2 b b_{1}(a+4 \Delta a)\right]+\left(b_{1}+b_{2}\right)^{2}\left(2 b_{1}+3 b_{2}\right)^{2} k_{1}^{2}}{4\left(b_{1}+b_{2}\right)^{2}\left(b_{1}+2 b_{2}\right)} .\right. \\
& \left.\frac{\left.\left(2 b_{1}+3 b_{2}\right)\left[2 b_{1}(a+\Delta a)(1-\mu)-b_{1} b_{2}\left(c+k_{1}\right)+b_{2}(a+\Delta a)(1-2 \mu)-b_{2}^{2}\left(c+k_{1}\right)\right]^{2}\right]}{4\left(b_{1}+b_{2}\right)^{2}\left(_{1}+2 b_{2}\right)^{2}}\right]
\end{aligned}
$$


Thus, $p_{1}^{T P *}=p^{*}, \quad q_{11}^{T P *}=q_{1}^{*}$, and $q_{21}^{T P^{*}}=q_{2}^{*}$.

Then, the dual-channel supply chain is coordinated by the two-part-tariff contract $\left(w_{1}^{*}, T_{1}^{*}\right)$.

For the case 2 and case 3 , if $-k_{2}\left(b_{1}+b_{2}\right)<\Delta a<k_{1}\left(b_{1}+b_{2}\right)$,

the optimal wholesale price is $w_{2}^{*}=w_{3}^{*}=\frac{a+2 \Delta a}{\left(b_{1}+b_{2}\right)}+c-\frac{(1-\mu)(a+\Delta a)}{b_{2}}$, and the range of the transfer payment is

$$
T_{2}^{*}=T_{3}^{*} \in\left[\frac{\left[b_{2}^{2} c-(a+\Delta a)\left(2 b_{1}+b_{2}\right)+b_{1} b_{2} c+2 \mu(a+\Delta a)\left(b_{1}+b_{2}\right)\right]^{2}}{4\left(b_{1}+b_{2}\right)^{2}\left(b_{1}+2 b_{2}\right)}, \frac{\left(2 b_{1}+3 b_{2}\right)\left[b_{2}^{2} c-(a+\Delta a)\left(2 b_{1}+b_{2}\right)+b_{1} b_{2} c+2 \mu(a+\Delta a)\left(b_{1}+b_{2}\right)\right]^{2}}{4\left(b_{1}+b_{2}\right)^{2}\left(b_{1}+2 b_{2}\right)^{2}}\right]
$$

Thus, $p_{2}^{T P^{*}}=p_{3}^{T P *}=p^{*}, \quad q_{12}^{T P^{*}}=q_{13}^{T P^{*}}=q_{1}^{*}, \quad$ and $\quad q_{22}^{T P^{*}}=q_{23}^{T P^{*}}=q_{2}^{*}$.

Then, the dual-channel supply chain is coordinated by the two-part-tariff contract $\left(w_{2}^{*}, T_{2}^{*}\right)$ and the two-part-tariff contract $\left(w_{3}^{*}, T_{3}^{*}\right)$.

For the case 4 , if $\Delta a \leq-k_{2}\left(b_{1}+b_{2}\right)$,

the optimal wholesale price is $w_{4}^{*}=\frac{a+\Delta a}{\left(b_{1}+b_{2}\right)}+c-k_{2}-\frac{(1-\mu)(a+\Delta a)}{b_{2}}$ and the range of the transfer payment is

$T_{4}^{*} \in\left[\frac{\left[2 b_{1}(a+\Delta a)(1-\mu)-c b_{1} b_{2}+b_{2}(a+\Delta a)(1-2 \mu)-c b_{2} b_{2}\right]^{2}+2\left(b_{1}+b_{2}\right) k_{2}\left[2 \Delta a b_{1}^{2}+(a+5 \Delta a) b_{2}^{2}-2 \mu b_{2}\left(b_{1}+b_{2}\right)(a+\Delta a)-c\left(b_{1}+b_{2}\right) b_{2}^{2}+2 b_{1} b_{2}(a+4 \Delta a)\right]+\left(b_{1}+b_{2}\right)^{2}\left(2 b_{1}+3 b_{2}\right)^{2} k_{2}^{2}}{4\left(b_{1}+b_{2}\right)^{2}\left(b_{1}+2 b_{2}\right)}\right.$

$\frac{\left(2 b_{1}+3 b_{2}\right)\left[2 b_{1}(a+\Delta a)(1-\mu)-b_{1} b_{2}\left(c-k_{2}\right)+b_{2}(a+\Delta a)(1-2 \mu)-b_{2}^{2}\left(c-k_{2}\right)\right]^{2}}{4\left(b_{1}+b_{2}\right)^{2}\left(b_{1}+2 b_{2}\right)^{2}}$

Thus, $p_{4}^{T P^{*}}=p^{*}, q_{14}^{T P^{*}}=q_{1}^{*}$, and $q_{24}^{T P^{*}}=q_{2}^{*}$.

Then, the dual-channel supply chain is coordinated by the two-part-tariff contract $\left(w_{4}^{*}, T_{4}^{*}\right)$.

As is shown above, the two-part-tariff contract used above can coordinate the decentralized supply chain when demand disruption occurs.

\section{Numerical Examples}

Let $a=1000$ (the market scale of a given product), $b_{1}=10, b_{2}=20$ (the channel price response factor), $\mu=0.4$ (the online market share), $c=20$ (the unit production cost), $k_{1}=k_{2}=5$ (the unit cost which deviates from the original production plan). Several numerical examples are given to illustrate the results derived in this paper when different demand disruptions happen.

If the manufacturer uses the two-part-tariff policy in this paper when demand disruption happens, then the total profits in the decentralized supply chain and those in the centralized decision are shown in Table 2.

Table 2 Parameters under Decentralized Decision and Centralized Decision in the Supply Chain when the Manufacturer Deals with Demand Disruption

\begin{tabular}{|c|c|c|c|c|c|c|c|c|c|c|}
\hline$\Delta a$ & Case & $p^{*}$ & $p^{T P^{*}}$ & $w^{*}$ & $q_{1}{ }^{*}$ & $q_{2}$ & $Q^{*}$ & $T^{*}$ & $\pi_{d}+\pi_{r}$ & $\Pi$ \\
\hline 0 & 2 & 26.67 & 26.67 & 23.33 & 133.33 & 66.67 & 200 & {$[89,144]$} & 1333.33 & 1333.33 \\
\hline 300 & 1 & 34.17 & 34.17 & 29.33 & 178.33 & 96.67 & 275 & {$[-563,299]$} & 3895.83 & 3895.83 \\
\hline 200 & 1 & 32.5 & 32.5 & 29 & 155 & 70 & 225 & {$[13,157]$} & 2812.5 & 2812.5 \\
\hline 100 & 2 & 30 & 30 & 27 & 140 & 60 & 200 & {$[174,279]$} & 2000 & 2000 \\
\hline 50 & 2 & 28.33 & 28.33 & 25.17 & 136.67 & 63.33 & 200 & {$[128,205]$} & 1666.67 & 1666.67 \\
\hline-50 & 3 & 25 & 25 & 21.5 & 130 & 70 & 200 & {$[57,91]$} & 1000 & 1000 \\
\hline-100 & 3 & 23.33 & 23.33 & 19.67 & 126.67 & 73.33 & 200 & {$[32,51]$} & 666.67 & 666.67 \\
\hline-200 & 4 & 20.83 & 20.83 & 17.67 & 111.67 & 63.33 & 175 & {$[128,395]$} & 145.83 & 145.83 \\
\hline
\end{tabular}




\begin{tabular}{|l|l|l|l|l|l|l|l|l|l|l|}
\hline-300 & 4 & 19.17 & 19.17 & 17.33 & 88.33 & 36.67 & 125 & {$[43,512]$} & -104.17 & -104.17 \\
\hline
\end{tabular}

As is shown in Table 2, the supply chain can be coordinated under the two-part-tariff contract used in this paper when demand disruption occurs.

\section{Conclusions}

This paper studies a dual-channel supply chain consisting of one manufacturer and one traditional retailer, in which the manufacturer is the leader of the Stackelberg game and sets the same retail price in the online channel as that in the offline channel. The manufacturer has its own online channel when he sells its product to the offline retailer. The optimal retail price and the sale quantity are obtained when the supply chain is in static state. Then some unexpected events make the consumer's demand change in the supply chain. We design a two-part-tariff contract with a one-time transfer payment to coordinate the supply chain under the demand disruption. The results are as follows: there exists certain robustness both in the manufacturer's production quantity and in the offline retail price when the deviation of demand is relatively small. If the change of the consumer's demand is large enough, the manufacturer needs to adjust the corresponding retail price and production quantity according to the two-part-tariff contract we design in this paper. Some numerical examples are also presented.

The disruption management in dual-channel supply chain is a meaningful and interesting field. There are still a lot of problems that need to be studied. For example, how to coordinate the dual-channel supply chain when the demand and cost disruption happens simultaneously is a very interesting question.

\section{Conflict of Interests}

The authors declare that there is no conflict of interests regarding the publication of this paper.

\section{Acknowledgement}

This research was supported by National Natural Science Funds of China (No. 70773017), Humanities and Social Sciences Foundation of Chinese Ministry of Education (No. 11YJA630141 and 12YJA630174), Research Fund for the Doctoral Program of Higher Education of China (No. 20110185110022).

\section{References}

[1]. T. Boyacı and G. Gallego, "Coordinating pricing and inventory replenishment policies for one wholesaler and one or more geographically dispersed retailers", International Journal of Production Economics, vol. 77, no. 2, (2002), pp. 95-111.

[2]. Cachon and P. Gérard, "Stock wars: inventory competition in a two-echelon supply chain with multiple retailers", Operations Research, vol. 49, (2001), pp. 658-674.

[3]. Cachon and P. Gerard, "Supply chain coordination with contracts", Handbooks in operations research and management science, vol. 11, (2003), pp. 227-339.

[4]. Cai and G. George, "Channel selection and coordination in dual-channel supply chains", Journal of Retailing, vol. 86, no. 1, (2010), pp. 22-36.

[5]. Cao and Erbao, et al., "Contracting with asymmetric cost information in a dual-channel supply chain", Operations Research Letters, vol. 41, no. 4, (2013), pp. 410-414.

[6]. J. Chen, H. Zhang and Y. Sun, "Implementing coordination contracts in a manufacturer Stackelberg dual-channel supply chain", Omega, vol. 40, no. 5, (2012), pp. 571-583.

[7]. Chen, K. Yut, M. Kaya and Ö. Özer, "Dual sales channel management with service competition", Manufacturing \& Service Operations Management, vol. 10, no. 4, (2008), pp. 654-675.

[8]. Chiang, W.-Y. Kevin, D. Chhajed and J. D. Hess, "Direct marketing, indirect profits: A strategic analysis of dual-channel supply-chain design", Management Science, vol. 49, no .1, (2003), pp. 1-20.

[9]. Chiang, W.-Y Kevin and G. E. Monahan, "Managing inventories in a two-echelon dual-channel supply chai,” European Journal of Operational Research, vol. 162, no. 2, (2005), pp. 325-341. 
[10]. Choi and S. Chan, "Price competition in a duopoly common retailer channel", Journal of retailing, vol. 72, no. 2, (1996), pp. 117-134.

[11].Dumrongsiri and Aussadavut, et al., "A supply chain model with direct and retail channels", European Journal of Operational Research, vol. 187, no. 3, (2008), pp. 691-718.

[12].Q. Geng and S. Mallik, "Inventory competition and allocation in a multi-channel distribution system", European Journal of Operational Research, vol. 182, no. 2, (2007), pp. 704-729.

[13].G. Hua, S. Wang and T. C E. Cheng, "Price and lead time decisions in dual-channel supply chains", European Journal of Operational Research, vol. 205, no. 1, (2010), pp. 113-126.

[14].Huang and Chongchao, et al., "Disruption management for supply chain coordination with exponential demand function”, Acta Mathematica Scientia, vol. 26, no. 4, (2006), pp. 655-669.

[15].S. Huang, C. Yang and H. Liu, "Pricing and production decisions in a dual-channel supply chain when production costs are disrupted", Economic Modelling, vol. 30, (2013), pp. 521-538.

[16].S. Huang, C. Yang and X. Zhang, "Pricing and production decisions in dual-channel supply chains with demand disruptions", Computers \& Industrial Engineering, vol. 62, no. 1, (2012), pp. 70-83.

[17].D. Lei, J. Li and Z. Liu, "Supply chain contracts under demand and cost disruptions with asymmetric information", International Journal of Production Economics, vol. 139, no. 1, (2012), pp. 116-126.

[18].W.-M. Ma, Z. Zhao and H. Ke, "Dual-channel closed-loop supply chain with government consumption-subsidy", European Journal of Operational Research, vol. 226, no. 2, (2013), pp. 221-227.

[19].Mukhopadhyay, K. Samar, X. Zhu and X. Yue, "Optimal contract design for mixed channels under information asymmetry", Production and Operations Management, vol. 17, no. 6, (2008), pp. 641-650.

[20].X. Qi, J. F. Bard and G. Yu, "Disruption management for machine scheduling: the case of SPT schedules", International Journal of Production Economics, vol. 103, no. 1, (2006), pp. 166-184.

[21].X. Qi, J. F. Bard and G. Yu, "Supply chain coordination with demand disruptions", Omega, vol. 32, no. 4, (2004), pp. 301-312.

[22].Ryan, K. Jennifer, D. Sun and X. Zhao, "Coordinating a Supply Chain with a Manufacturer-Owned Online Channel: A Dual Channel Model under Price Competition", IEEE Transactions on Engineering Management, vol. 60, no. 2, (2013), pp. 247-259.

[23].Takahashi and Katsuhiko, et al., "Inventory control in a two-echelon dual-channel supply chain with setup of production and delivery", International Journal of Production Economics, vol. 133, no. 1, (2011), pp. 403-415.

[24].Tsay, A. Andy and N. Agrawal, "Channel Conflict and Coordination in the E- Commerce Age", Production and Operations Management, vol. 13, no. 1, (2004), pp. 93-110.

[25].T. Xiao and X. Qi, "Price competition, cost and demand disruptions and coordination of a supply chain with one manufacturer and two competing retailers", Omega, vol. 36, no. 5, (2008), pp. 741-753.

[26].T. Xiao and G. Yu, "Supply chain disruption management and evolutionarily stable strategies of retailers in the quantity-setting duopoly situation with homogeneous goods", European Journal of Operational Research, vol. 173, no. 2, (2006), pp. 648-668.

[27].T. Xiao, et al., "Coordination of a supply chain with one-manufacturer and two-retailers under demand promotion and disruption management decisions", Annals of Operations Research, vol. 135, no. 1, (2005), pp. 87-109.

[28].T. Xiao, X. Qi and G. Yu, "Coordination of supply chain after demand disruptions when retailers compete", International Journal of Production Economics, vol. 109, no. 1, (2007), pp. 162-179.

[29].G. Xu, et al., "Coordinating a dual-channel supply chain with risk-averse under a two-way revenue sharing contract", International Journal of Production Economics, vol. 147, (2014), pp. 171-179.

[30].Xu and Minghui, et al., "Coordinating dyadic supply chains when production costs are disrupted", IIE transactions, vol. 38, no. 9, (2006), pp. 765-775.

[31].J. Yang, X. Qi and G. Yu, "Disruption management in production planning", Naval Research Logistics (NRL), vol. 52, no. 5, (2005), pp. 420-442.

[32]. Yao and D. Qing, et al., "Strategic inventory deployment for retail and e-tail stores", Omega, vol. 37, no. 3, (2009), pp. 646-658.

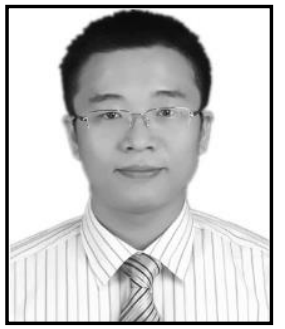

Xiaozhi Wu, was born in Fujian Province, China, 1981, he received his master's degree of management science and engineering in University of Electronic Science and Technology of China, Chengdu, China (2009). Now he is a PhD Candidate in UESTC and lecturer of logistics management in Zhongshan Polytechnic, Zhongshan, China. His research interests include supply chain management and e-commerce. 
International Journal of $u-$ and $e-$ Service, Science and Technology Vol.8, No.2 (2015) 